\title{
Lazaroid U-74389F attenuates phorbol ester-induced lung injury in rabbits
}

\author{
M. Miniati*, F. Cocci**, S. Monti*, E. Filippi*, R. Sarnelli+, M. Ferdeghini++, \\ V. Gattai*, M. Pistolesi ${ }^{\#}$
}

Lazaroid U-74389F attenuates phorbol ester-induced lung injury in rabbits. M. Miniati, F. Cocci, S. Monti, E. Filippi, R. Sarnelli, M. Ferdeghini, V. Gattai, M. Pistolesi. (CERS Journals Ltd 1996.

ABSTRACT: We examined the effect of the antioxidant lazaroid U-74389F on acute lung injury induced in rabbits by phorbol myristate acetate (PMA).

Thirty minutes after receiving either $\mathrm{U}-74389 \mathrm{~F}\left(15 \mathrm{mg}^{-\mathrm{kg}^{-1}}\right.$ i.v. $)$ or $\mathrm{U}-74389 \mathrm{~F}$ vehicle, rabbits $(\mathrm{n}=60)$ were given PMA $\left(60 \mu \mathrm{g}^{\circ} \mathrm{kg}^{-1}\right.$ i.v. $)$. PMA vehicle injected rabbits $(\mathbf{n}=20)$ served as controls. Over a $5 \mathrm{~h}$ period after PMA or PMA vehicle injection, we measured arterial $\mathrm{pH}$, arterial oxygen tension $\left(\mathrm{Pa}_{\mathrm{a}} \mathrm{O}_{2}\right)$, arterial carbon dioxide tension $\left(\mathrm{Pa}_{\mathrm{a}} \mathrm{CO}_{2}\right)$, and the plasma concentration of the neutrophil chemoattractant interleukin-8 (IL-8). At postmortem, lungs were inspected for macroscopic injury and examined histologically. Malondialdehyde levels were assayed in lung tissue as an index of lipid peroxidation. In bronchoalveolar lavage (BAL), total and differential cell counts, protein and IL-8 concentrations were measured.

Compared to normal controls, rabbits challenged with PMA alone developed arterial acidosis, hypercapnia and hypoxaemia, accompanied by significant rise in plasma IL-8 concentration. U-74389F pretreated animals did not develop significant arterial blood gas abnormalities and had significantly lower IL-8 concentration in plasma. U-74389F did not prevent PMA-induced lipid peroxidation. However, macroscopic signs of lung injury and the degree of alveolar haemorrhage and protein extravasation were significantly less severe in pretreated rabbits than in those given PMA alone. In addition, U-74389F significantly reduced IL-8 concentration and neutrophil number in BAL. By histological assessment, $80 \%$ of lung neutrophils were localized in alveolar spaces of animals receiving PMA alone. Conversely, in U-74389F pretreated animals, $75 \%$ of neutrophils were distributed within extraalveolar blood vessels and alveolar septa.

We conclude that lazaroid $\mathrm{U}-\mathbf{7 4 3 8 9}$ F attenuates lung injury in rabbits given PMA by preventing neutrophil migration into pulmonary alveoli. This effect may, in part, be related to downregulation of IL-8 production. Eur Respir J., 1996, 9, 758-764.
*Istituto di Fisiologia Clinica del CNR, **Istituto di Patologia Medica I, \#Istituto di Clinica Medica II, ++Centro Regionale di Medicina Nucleare, Università di Pisa, and + Scuola Superiore di Studi Universitari e Perfezionamento "S. Anna", Pisa, Italy.

Correspondence: M. Miniati

Reparto Polmonare

Istituto di Fisiologia Clinica del CNR

Via Savi 8

56100 Pisa

Italy

Keywords: 21-aminosteroids

interleukin-8

lazaroids

lung injury

neutrophils

phorbol myristate acetate

Received: June 71995

Accepted after revision December 201995

This work was supported in part by grants from the CNR Cardiorespiratory Group and from the CNR targeted project "Prevention and Control of Disease Factors" subproject 8 "Control of cardiovascular pathology" 8.5.1. No. 9103611-PF 41.
Lazaroids (21-aminosteroids) are a group of nonglucocorticoid analogues of methylprednisolone designed to penetrate the hydrophobic domains of cell membranes for the purpose of inhibiting lipid peroxidation $[1,2]$. In vivo efficacy of lazaroids has been documented in experimental models of traumatic injury of the central nervous system [3], ischaemia-reperfusion injury in a variety of organs [4-6], and haemorrhagic shock [7]. Lazaroids were also found to afford protection against E. coli-induced lung injury in guinea-pigs [8], and bleomycin-induced lung fibrosis in rats [9].

Recently published data indicate that lazaroids may exert their protective actions by mechanisms other than inhibition of lipid peroxidation. For instance, it has been shown that lazaroids possess a direct antioxidant activity by scavenging hydroxyl radicals [10], and by inhibiting production of oxygen radicals in human neutrophils stimulated in vitro with phorbol myristate acetate (PMA) [8, 10]. Also, it has been reported that lazaroids are capable of suppressing the expression of the neutrophil chemoattractant cytokine interleukin-8 (IL-8) in hyperoxiastimulated monocytes cultured in vitro [11]. The latter finding may be therapeutically relevant because IL- 8 has been implicated in the pathogenesis of a number of neutrophil-mediated lung disorders, including idiopathic pulmonary fibrosis $[12,13]$, and the adult respiratory distress syndrome (ARDS) [14, 15].

In the present study, we tested the in vivo efficacy of lazaroid U-74389F pretreatment in a rabbit model of neutrophil-dependent, acute lung injury induced by intravenous administration of PMA. In the rabbit, PMA causes sustained neutropenia and thrombocytopenia, acute respiratory distress, and haemorrhagic pneumonitis [16]. The latter resembles the histopathological lesions featuring human ARDS, and is characterized by massive accumulation of erythrocytes, leucocytes, and plasma proteins in alveolar spaces, which occurs within 1.5-5 h of PMA injection [16]. 
We first evaluated whether lazaroid U-74389F could attenuate lung injury and gas exchange impairment in PMA-treated rabbits. In related experiments, we also evaluated whether IL-8 is released in response to PMA challenge and whether IL-8 production is inhibited by lazaroid $\mathrm{U}-74389 \mathrm{~F}$ pretreatment.

\section{Methods}

\section{Chemicals}

Lazaroid U-74389F (21-[4-(2,6-di-1-pyrrolidinyl-4-pyrimidinyl)-1-piperazinyl]-pregna-1,4,9 (11)-triene-3, 20dione monomethane sulphonate) was a gift from Upjohn Company (Kalamazoo, MI, USA). It was dissolved in a citric acid solution $(0.02 \mathrm{M}$ citric acid monohydrate, $0.0032 \mathrm{M}$ sodium citrate dihydrate, $0.077 \mathrm{M}$ sodium chloride, $\mathrm{pH}$ 3.0) immediately before intravenous (i.v.) administration. Phorbol myristate acetate (12-O-tetradecanoyl/phorbol 13-acetate), purchased from Sigma Chemical Co. (St Louis, MO, USA), was dissolved in dimethylsulphoxide (DMSO) at a concentration of 2 $\mathrm{mg} \cdot \mathrm{mL}^{-1}$, and stored in $65 \mu \mathrm{L}$ aliquots at $-70^{\circ} \mathrm{C}$ until use. Potency of each new batch of PMA was checked by measuring superoxide anion production by neutrophils stimulated in vitro with PMA.

\section{Experimental protocol}

Eighty unanaesthetized New Zealand albino rabbits, weighing $2.0-2.5 \mathrm{~kg}$, were used throughout the study. The protocol was approved by the Institutional Animal Care Committee. In a first set of experiments, $50 \mathrm{rab}-$ bits were randomized into three groups as follows. Ten rabbits received an i.v. bolus of saline containing $65 \mu \mathrm{L}$ of DMSO (PMA vehicle) and served as normal controls. Forty rabbits were challenged with PMA $\left(60 \mu \mathrm{g} \cdot \mathrm{kg}^{-1}\right.$ i.v.). Twenty of these were pretreated with U-74389F (15 mg.kg-1 i.v.) $30 \mathrm{~min}$ before PMA. A dose of $15 \mathrm{mg} \cdot \mathrm{kg}^{-1}$ was chosen because, in preliminary experiments, it was observed that $\mathrm{U}-74389 \mathrm{~F}$ at $5 \mathrm{mg} \cdot \mathrm{kg}^{-1} i . v$. was ineffective in attenuating PMA-induced lung injury. In the remaining 20 rabbits, PMA administration was preceded 30 min earlier by an i.v. bolus of citric acid solution (U-74389F vehicle). Through an indwelling cannula, positioned in a central ear artery, blood samples were obtained under baseline conditions and at various time intervals over a period of $5 \mathrm{~h}$ after DMSO or PMA injection. The volume of blood withdrawn at any time was replaced by an equal volume of saline. Circulating leucocytes in the blood were measured by means of a Coulter counter (Coulter Corporation, Miami, FL, USA). Arterial $\mathrm{pH}$, arterial oxygen tension $\left(\mathrm{Pa}, \mathrm{O}_{2}\right)$ and arterial carbon dioxide tension $\left(\mathrm{Pa}_{\mathrm{a}}, \mathrm{CO}_{2}\right)$ were measured using an IL-1302 apparatus (Instrumentation Laboratories, Milano, Italy). By the end of the $5 \mathrm{~h}$ period of experimental observation, the rabbits were deeply anaesthetized with xylazine $\left(5 \mathrm{mg} \cdot \mathrm{kg}^{-1}\right)$ and ketamine $\left(25 \mathrm{mg} \cdot \mathrm{kg}^{-1}\right)$ administered intramuscularly, and were killed by exsanguination through the right carotid artery. Their lungs were excised, dissected free of major airways, blotted dry, and weighed. To correct for differences in body mass, the actual lung weight was normalized to body weight.

The macroscopic appearance of the lungs was noted and graded on a 5-point scale as follows: 0=lungs usually pink in colour without signs of focal haemorrhage; $1=$ sparse foci of petechial haemorrhage; 2 =numerous foci of petechial haemorrhage scattered throughout all lobes; 3=large, confluent haemorrhagic areas involving one or more lobes; 4=bilateral haemorrhagic consolidation usually accompanied by frothy oedema liquid emanating from the airways. The macroscopic grading of lung injury was made by a pathologist without knowledge of animal treatment.

Samples from the left lung were weighed and then dried to constant weight in a microwave oven to calculate the lung wet/dry weight ratio. The right lung was minced and homogenized in $10 \mathrm{vol}$ of saline with a Polytron PT-10 homogenizer (Kinematica, Luzern, Switzerland) for measuring malondialdehyde (MDA) concentration, as an index of lipid peroxidation.

An additional set of experiments was carried out to further characterize the effect of U-74389F pretreatment on the extent of PMA-induced lung injury by counting the number of neutrophils in lung tissue sections and by examining the cell and protein composition of bronchoalveolar lavage (BAL). Thirty rabbits were used for this study, and were randomized into three groups (10 animals each) as described previously. In these experiments, arterial blood samples were also obtained under baseline conditions, and at $1 \mathrm{~h}$ intervals up to $5 \mathrm{~h}$ after DMSO or PMA administration, to measure IL-8 concentration in the plasma. Blood samples $(1 \mathrm{~mL})$ were collected in test tubes containing $20 \mu \mathrm{L}$ of ethylenediamine tetra-acetic acid (EDTA) and $40 \mu \mathrm{L}$ of aprotinin, and were centrifuged at $650 \times \mathrm{g}$ for $10 \mathrm{~min}$ at $4^{\circ} \mathrm{C}$. The plasma fraction was stored in aliquots at $-70^{\circ} \mathrm{C}$ until assayed for IL-8 concentration as described below. All samples were separated from the cellular fraction and frozen within 20 min of being drawn.

By the end of the experiments, rabbits were anaesthetized and killed by exsanguination. The trachea was exposed and clamped shut. The lungs were then removed intact with the trachea, dissected free of other tissues, and inspected for macroscopic signs of injury as described above. A plastic tube was inserted into the trachea and the lungs were gently inflated with air until any sign of atelectasis had gone. A ligature was then placed around the right main-stem bronchus, and $20 \mathrm{~mL}$ of ice-cold phosphate-buffered saline was slowly instilled into the left lung via the endotracheal tube. The left lung was turned upside down and the lavage liquid was allowed to drain in a tared tube. Recovery of the lavage liquid averaged $63.9 \pm 0.9 \%$ of the instillate. There was no significant difference in the recovery of lavage liquid among the three groups of animals (DMSO 64.3 $\pm 1.4 \%$; PMA $64.4 \pm 1.8 \%$; U-74389F + PMA $63.0 \pm 1.0 \%$ ). The lavage liquid was centrifuged at $650 \times \mathrm{g}$ for $10 \mathrm{~min}$ at $4^{\circ} \mathrm{C}$. The cellular sediment was resuspended in $1.5 \mathrm{~mL}$ of normal saline and total cell counts (erythrocytes and leucocytes) were performed with a Coulter counter. Cytocentrifuge preparations of suitably diluted aliquots of the cell suspension were stained with May-Grünwald Giemsa, and differential leucocyte counts were performed by identifying at least 600 cells at $\times 1,000$ (magnification under 
oil). The supernatant of the retrieved lavage liquid was further centrifuged at $1,000 \times \mathrm{g}$ for $10 \mathrm{~min}$ at $4^{\circ} \mathrm{C}$ to remove cell debris. Aliquots of the final supernatant were taken to measure protein concentration by the BCA Protein Assay (Pierce Chemical Co., Rockford, IL, USA) using bovine serum albumin as a standard. Additional aliquots of the final supernatant were stored at $-70^{\circ} \mathrm{C}$ until assayed for IL-8 concentration as described below.

The right lung was fixed by intrabronchial infusion of $10 \%$ buffered formalin at a pressure of $20 \mathrm{cmH}_{2} \mathrm{O}$ for $24 \mathrm{~h}$. Paraffin embedded 6-8 $\mu \mathrm{m}$ cross-sections of the right lower lobe were stained with haematoxylin and eosin for histological analysis. Neutrophils within extraalveolar vessels (arterioles and venules), interalveolar septa, and alveolar spaces were counted on 10 high-power fields randomly selected from lung tissue sections. Differential cell counting in cytocentrifuge smears of BAL and neutrophil counting in histological sections of lung tissue were carried out by a pathologist without knowledge of the treatment received by the animals.

\section{Analytical procedures}

MDA in the lung tissue was assayed according to the method of OHKAWA et al. [17] as thiobarbituric acid (TBA) reacting substances (TBARS). Briefly, small aliquots of the lung homogenate $(0.2 \mathrm{~mL})$ were mixed with $0.2 \mathrm{~mL}$ of $8.1 \%$ sodium dodecylsulphate, $1.5 \mathrm{~mL}$ of $20 \%$ acetic

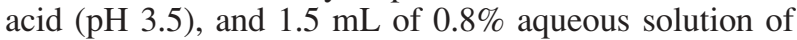
$\mathrm{TBA}$, and were heated at $95^{\circ} \mathrm{C}$ for $60 \mathrm{~min}$. After cooling, the chromogen was extracted with n-butanol-pyridine mixture (15:1 by volume), and its spectrum was recorded over the $400-600 \mathrm{~nm}$ range to correct for possible background absorption due to the interference of thermal or acid-catalysed decomposition of pre-existing oxidation precursors [18]. TBARS concentration in the lung was calculated from the absorption at $532 \mathrm{~nm}$ using a molar extinction coefficient of $1.56 \cdot 10^{5}$ [19], and was expressed as $\mathrm{nmol} \cdot \mathrm{g}^{-1}$ wet weight.

IL-8 concentration in plasma and in BAL was measured by means of a commercially available solid phase enzyme amplified sensitivity immunoassay (EASIA) performed on microtitre plates (IL-8 EASIA; Medgenix Diagnostics, Fleurus, Belgium). This method is based on the use of several monoclonal antibodies (MoAbs) directed against distinct epitopes of IL-8; thereby, avoiding hyperspecificity and allowing highly sensitive assays with extended standard range and short incubation time. Ninety six well polystyrene microtitre plates, precoated with murine MoAbs directed against human IL-8, were used. Human recombinant IL-8, in dilutions ranging $7-750 \mathrm{pg} \cdot \mathrm{mL}^{-1}$, was used to generate a standard curve for the assay. After rinsing the wells with buffer solution, $100 \mu \mathrm{L}$ of the standard or of the sample (plasma or lavage liquid) were added in duplicate to the appropriate well. Next, $50 \mu \mathrm{L}$ of MoAbs labelled with horseradish peroxidase (HRP) were dispensed into all wells. The plates were incubated at room temperature for $2 \mathrm{~h}$ on a horizontal shaker and then washed three times with $400 \mu \mathrm{L}$ of phosphate-buffered saline (PBS) containing $0.1 \%$ Tween to remove unbound HRP-labelled MoAbs. Two hundred microlitres of the revelation solution (tetramethylbenzidine-hydrogen peroxide) were added to each well, followed by a $30 \mathrm{~min}$ colour development stage at room temperature. The reaction was stopped by adding $50 \mu \mathrm{L}$ of $1.8 \mathrm{~N}$ sulphuric acid per well. Optical densities were determined within 10 min using a microtitre plate-reading spectrophotometer (ETI-System Reader; Sorin Biomedica, Saluggia, Italy) at $450 \mathrm{~nm}$ wavelength. A four-parameter logistic function was used to construct the standard curve, and IL- 8 concentration in plasma and in BAL was determined by interpolation on the standard curve. The limit of detection of IL- 8 with this assay is $0.7 \mathrm{pg} \cdot \mathrm{mL}^{-1}$.

\section{Statistical analysis}

The measured variables are reported in the text and in the figures as means \pm standard error of the mean (SEM). Nonparametric Mann-Whitney U-test, Chi-squared test (exact Fisher's test), and paired t-test were used to determine statistical differences among the groups. A p-value lower than 0.05 was accepted as statistically significant.

\section{Results}

The administration of PMA resulted in severe leucopenia (90\% decrease compared to baseline values) which was not prevented by U-74389F pretreatment (fig. 1). By $5 \mathrm{~h}$ after PMA injection, the circulating leucocyte counts returned to within preinjection values (fig. 1). DMSO injection had no effect on circulating leucocyte counts.

When compared to DMSO-injected controls, rabbits given PMA alone developed a significant decrease in arterial $\mathrm{pH}$, which reached a nadir at $120 \mathrm{~min}$ after PMA injection as depicted in figure 2a. Significant arterial acidosis persisted throughout the experiments. Likewise, significant and persistent hypoxaemia and hypercapnia became evident by $120 \mathrm{~min}$ after PMA administration (fig. $2 b$ and 2c).

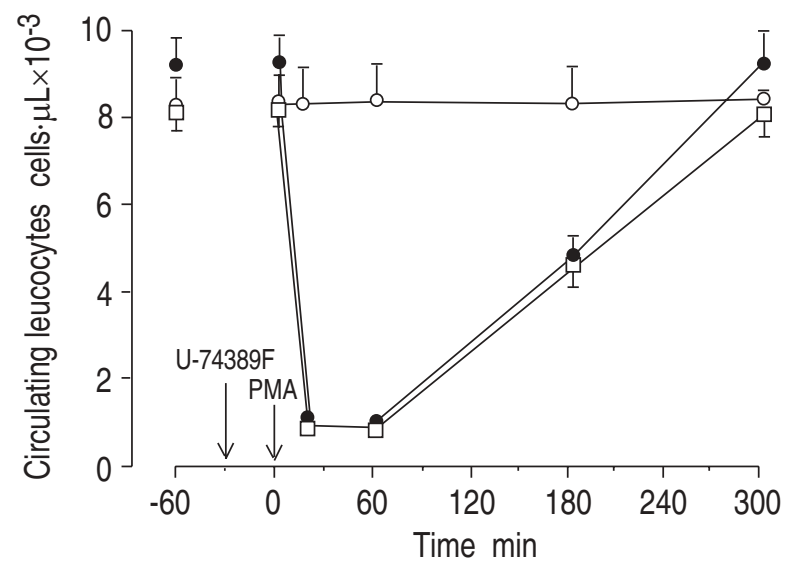

Fig. 1. - Time-course of circulating leucocytes in DMSO-injected rabbits $(\mathrm{n}=10$; —- $)$, PMA-injected rabbits $(\mathrm{n}=20$; - $\longrightarrow$ ), and rabbits pretreated with U-74389F 30 min before PMA administration $(\mathrm{n}=20 ;-\square-(-)$. Symbols at $-60 \mathrm{~min}$ refer to measurements obtained at baseline in the three groups. Values are presented as mean \pm SEM. Arrows mark the time-points at which U-74389F (15 mg.kg-1) and PMA $\left(60 \mu \mathrm{g} \cdot \mathrm{kg}^{-1}\right)$ were administered intravenously. DMSO: dimethyl sulphoxide; PMA: phorbol myristate acetate. 
At necropsy, the lung weight/body weight ratio in these animals was greater than that of control rabbits, whereas no difference was observed in the lung wet/dry weight ratio (table 1). The latter finding reflects the inflammatory nature of PMA-induced lung oedema characterized by massive extravasation of blood cells and plasma proteins [16].

a)

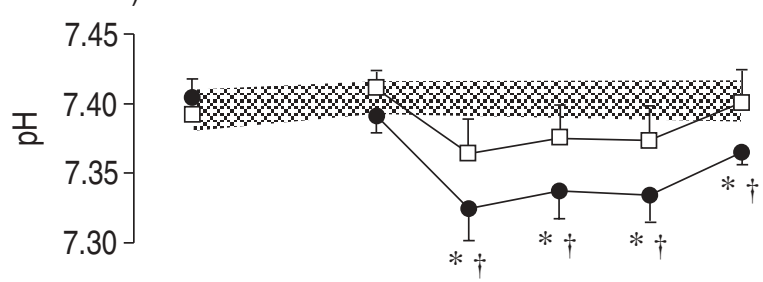

b)
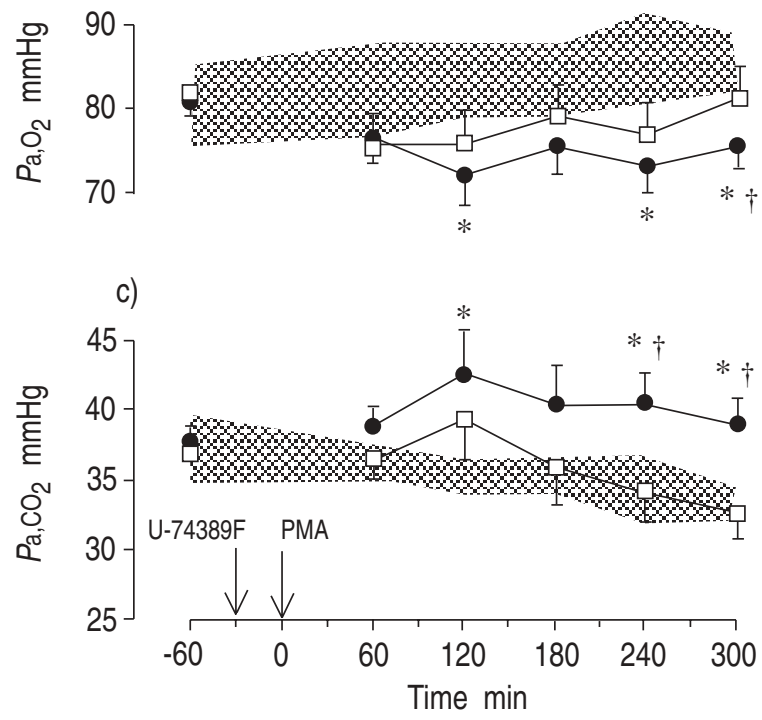

Fig. 2. - Time-course of: a) arterial $\mathrm{pH}$; b) arterial oxygen tension $\left(\mathrm{Pa}_{\mathrm{a}} \mathrm{O}_{2}\right)$; and $\left.\mathrm{c}\right)$ arterial carbon dioxide tension $\left(\mathrm{P}_{\mathrm{a}}, \mathrm{CO}_{2}\right)$ in PMA-injected rabbits $(\mathrm{n}=20$; — $)$, and rabbits pretreated with U-74389F 30 min before PMA administration $(\mathrm{n}=20 ;-\square-)_{-}$. Symbols at $-60 \mathrm{~min}$ refer to the arterial blood gas measurements obtained at baseline in the two groups of animals. Values are presented as mean \pm SEM. The stippled areas refer to the normal range (mean $\pm 2 \mathrm{SEM}$ ) of $\mathrm{pH}, \mathrm{Pa}_{\mathrm{a}} \mathrm{O}_{2}$, and $P \mathrm{a}, \mathrm{CO}_{2}$ measured in DMSO-injected rabbits $(\mathrm{n}=10)$. $*: \leq \mathrm{p}<0.05$, by Mann-Whitney U-test, between rabbits given PMA alone and DMSOinjected controls at the time-points indicated; $\uparrow: \leq p<0.05$ between rabbits given PMA alone and those pretreated with U-74389F. Arrows mark the time-points at which U-74389F (15 mg.kg-1) and PMA (60 $\left.\mu \mathrm{g} \cdot \mathrm{kg}^{-1}\right)$ were administered intravenously. For abbreviations see legend to figure 1 .
As opposed to animals receiving PMA alone, rabbits pretreated with U-74389F did not develop arterial acidosis or hypercapnia (fig. 2a and c). Transient arterial hypoxaemia occurred in the first $2 \mathrm{~h}$ following PMA administration, but the actual $\mathrm{Pa}, \mathrm{O}_{2}$ values did not significantly differ from those of DMSO-injected rabbits (fig. 2b).

Although both the lung weight/body weight ratio and the lung wet/dry weight ratio were comparable to those of rabbits administered with PMA alone, the extent of lung damage - as judged by gross inspection of the lungs - was significantly less severe in rabbits pretreated with U-74389F (table 1). Indeed, $50 \%$ of the pretreated animals showed minimal macroscopic signs of lung injury (score $0-1$ ) as opposed to only $17 \%$ of the rabbits given PMA alone ( $\mathrm{p}=0.0053$, by exact Fisher's test). In the latter group, $43 \%$ of the animals presented severe macroscopic lung damage (score 3-4). Such severe lung injury occurred only in $6(20 \%)$ of the 30 rabbits pretreated with U-74389F ( $\mathrm{p}=0.0348$, by exact Fisher's test).

TBARS concentration in the lung, taken as an index of lipid peroxidation, was equally increased both in rabbits given PMA alone and in those pretreated with U74389F compared to DMSO-injected rabbits (table 1).

BAL data in the three groups of rabbits are reported in table 2. Compared to DMSO-injected controls, rabbits given PMA alone had a significantly higher number of erythrocytes and leucocytes in the lavage liquid. Likewise, the fraction of neutrophils in the lavage was significantly increased over that of DMSO controls, as was the protein concentration. In rabbits pretreated with U-74389F, the degree of alveolar haemorrhage and protein extravasation was significantly less severe than in those challenged with PMA alone (table 2). Although the total leucocyte counts were comparable to those of rabbits given PMA alone, U-74389F pretreated animals had a significantly lower fraction of neutrophils in the lavage liquid (table 2). Indeed, the absolute number of neutrophils $\mu \mathrm{L}^{-1}$ of lavage liquid was reduced by approximately $60 \%$ in rabbits pretreated with U-74389F compared to those receiving PMA alone $(2687 \pm 625 \mathrm{vs}$ $7765 \pm 1204$; $\mathrm{p}<0.01$ ).

Considering the three groups of animals together, there was a significant, positive correlation between protein concentration in the lavage and the fraction of lavage cells that were neutrophils $(n=30 ; r=0.87 ; p<0.001)$.

BAL findings were confirmed by histological examination of lung tissue specimens. The cumulative number of neutrophils in 10 randomly selected high-power lung fields was significantly increased $(\mathrm{p}<0.001)$ both in rabbits given PMA alone (1203 \pm 100$)$ and in those pretreated

Table 1. - Postmortem measured variables in DMSO- and PMA-injected rabbits

\begin{tabular}{lcccc}
\hline Group & $\begin{array}{c}\text { Lung wt/body wt } \\
\text { ratio }\end{array}$ & $\begin{array}{c}\text { Lung wet/dry wt } \\
\text { ratio }\end{array}$ & $\begin{array}{c}\text { Lung injury } \\
\text { score }\end{array}$ & $\begin{array}{c}\text { TBARS } \\
\mathrm{nmol \cdot g} \text {-1 }^{-1} \text { lung }\end{array}$ \\
\hline DMSO & $3.98 \pm 0.10$ & $5.37 \pm 0.06$ & 0 & $103 \pm 6$ \\
PMA & $6.04 \pm 0.49^{*}$ & $5.43 \pm 0.07$ & $2.46 \pm 0.16^{*}$ & $159 \pm 8^{*}$ \\
U-74389F & $5.65 \pm 0.46^{*}$ & $5.39 \pm 0.12$ & $1.77 \pm 0.21^{* \dagger}$ & $156 \pm 7^{*}$ \\
+ PMA & & & & \\
\hline
\end{tabular}

Values are presented as mean \pm SEM. TBARS: thiobarbituric acid reactive substances; DMSO: dimethyl sulphoxide; PMA: phorbol myristate acetate. *: $\mathrm{p}<0001$ versus $\mathrm{DMSO}{ }^{\dagger}: \mathrm{p}<0.01$ versus PMA (MannWhitney U-test). 
Table 2. - Bronchoalveolar lavage data in DMSO- and PMA-injected rabbits

\begin{tabular}{|c|c|c|c|c|c|}
\hline Group & $\begin{array}{c}\text { Erythrocytes/ } \\
\quad \mu \mathrm{L} \times 10^{-4}\end{array}$ & $\begin{array}{l}\text { Leucocytes/ } \\
\mu \mathrm{L} \times 10^{-3}\end{array}$ & $\begin{array}{c}\text { Neutrophils } \\
\%\end{array}$ & $\begin{array}{l}\text { Protein } \\
\mathrm{mg} \cdot \mathrm{mL}^{-1}\end{array}$ & $\begin{array}{c}\text { IL-8 } \\
\mathrm{pg} \cdot \mathrm{mL}^{-1}\end{array}$ \\
\hline DMSO & $2.4 \pm 0.3$ & $8.2 \pm 1.0$ & $0.6 \pm 0.3$ & $0.8 \pm 0.1$ & $3.5 \pm 0.3$ \\
\hline PMA & $32.9 \pm 7.7 *$ & $15.8 \pm 1.3 *$ & $47.2 \pm 5.4^{*}$ & $5.4 \pm 1.2 *$ & $34.7 \pm 11.9^{\$}$ \\
\hline $\begin{array}{l}\text { U-74389F } \\
+ \text { PMA }\end{array}$ & $13.7 \pm 3.9 * \dagger$ & $13.5 \pm 1.6^{*}$ & $19.4 \pm 3.5^{\text {*\# }}$ & $1.9 \pm 0.5 * \dagger$ & $6.9 \pm 1.8^{\dagger}$ \\
\hline
\end{tabular}

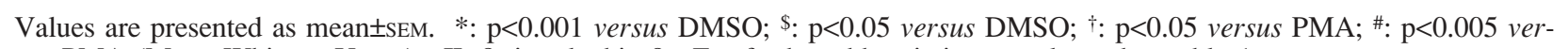
sus PMA (Mann-Whitney U-test). IL-8: interleukin-8. For further abbreviations see legend to table 1.

with U-74389F $(966 \pm 192)$ with respect to DMSO-injected controls (240 \pm 32$)$. However, a remarkable difference between the two groups of PMA-treated rabbits became evident when looking at the relative distribution of neutrophils in the three lung compartments examined (fig. 3). In rabbits receiving PMA alone, nearly $80 \%$ of the neutrophils were distributed in the alveolar spaces. In contrast, in those animals pretreated with U-74389F, 75\% of the neutrophils were localized within extra-alveolar blood vessels and interalveolar septa (fig. 3).

The time course of IL- 8 appearance in the rabbit systemic circulation is shown in figure 4 . IL-8 was not detectable in the plasma at any time after DMSO injection. Conversely, IL-8 concentration rose significantly above baseline values by $60 \mathrm{~min}$ after PMA challenge. It should be considered that the monoclonal antibodies employed in the assay were directed against human, not rabbit IL-8. It was fortunate, therefore, that these antibodies did cross-react with rabbit IL-8, but not entirely unexpected given the high degree of homology of IL-8 among different species [20]. In rabbits given PMA alone, IL-8 plasma concentration peaked to a mean value of $22 \pm 4 \mathrm{pg} \cdot \mathrm{mL}^{-1}$ at $120 \mathrm{~min}(\mathrm{p}<0.001$ versus baseline), and returned to baseline values by $5 \mathrm{~h}$ after PMA injection. In U-74389F pretreated rabbits, IL-8 plasma concentration at $120 \mathrm{~min}\left(7 \pm 2 \mathrm{pg} \cdot \mathrm{mL}^{-1}\right)$ was significantly

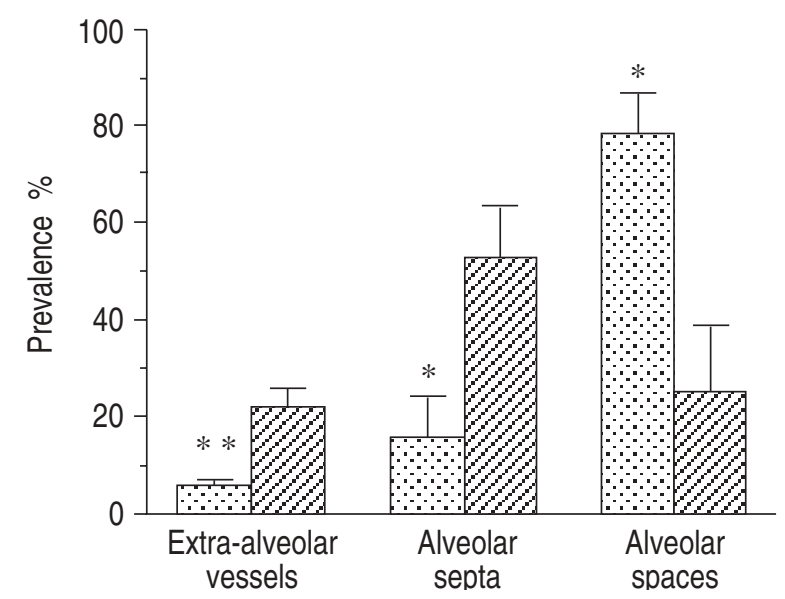

Fig. 3. - Relative distribution of neutrophils in three compartments of the rabbit lung: extra-alveolar vessels; interalveolar septa; and alveolar spaces. Neutrophils in each compartment are expressed as percentage of the cumulative number of neutrophils measured in 10 randomly selected high-power lung fields. $\square$ : rabbits given PMA alone $(\mathrm{n}=10)$. $\square$ : rabbits pretreated with $\mathrm{U}-74389 \mathrm{~F}\left(15 \mathrm{mg} \cdot \mathrm{kg}^{-1}\right.$ i.v. $)$ 30 min before PMA administration $(\mathrm{n}=10)$. Bars represent the mean value ( \pm SEM) of the relative neutrophil distribution in each lung compartment in the two groups of rabbits. *: $\mathrm{p}<0.05$; **: $\mathrm{p}<0.01$, by MannWhitney U-test, between the two groups. PMA: phorbol myristate acetate.

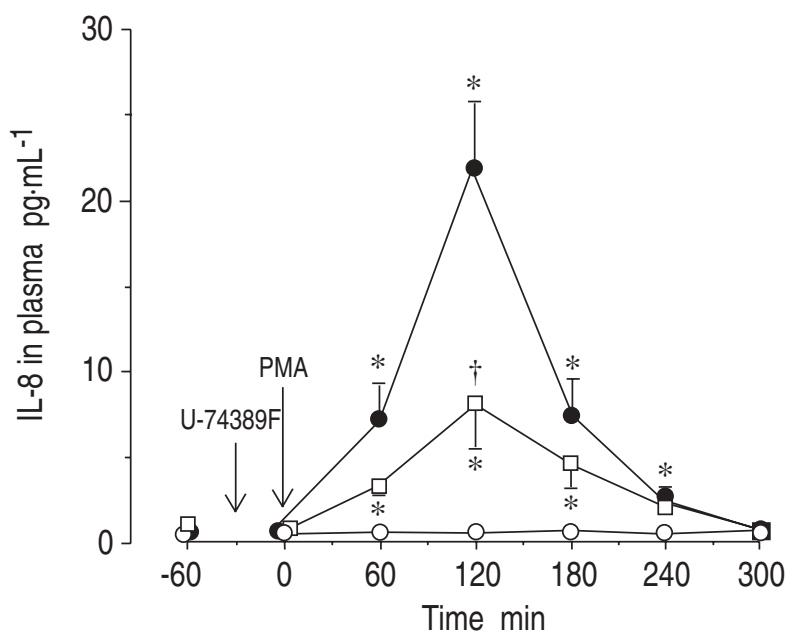

Fig. 4. - Time-course of interleukin-8 (IL-8) concentration in the plasma of DMSO-injected rabbits $(n=10 ;-O-)$, PMA-injected rabbits $(\mathrm{n}=10 ;--)$, and rabbits pretreated with $\mathrm{U}-74389 \mathrm{~F} 30 \mathrm{~min}$ before PMA administration $(n=10 ;-\square-)$ ). Symbols at -60 min refer to measurements obtained at baseline in the three groups. Values are presented as mean \pm SEM. $*: \leq \mathrm{p}<0.05$ by paired $\mathrm{t}$-test from those obtained at baseline; $\dagger: \mathrm{p}=0.01$ between rabbits given PMA alone and those pretreated with U-74389F. Arrows mark the time-points at which U$74389 \mathrm{~F}\left(15 \mathrm{mg} \cdot \mathrm{kg}^{-1}\right)$ and PMA $\left(60 \mu \mathrm{g} \cdot \mathrm{kg}^{-1}\right)$ were administered intravenously. For abbreviations see legend to figure 1 .

lower $(\mathrm{p}=0.01)$ than the corresponding value measured in rabbits given PMA alone.

IL-8 concentration in BAL was significantly increased in rabbits given PMA alone compared both to DMSO controls and to rabbits pretreated with U-74389F (table 2).

\section{Discussion}

The present in vivo experiments indicate that lazaroid $\mathrm{U}-74389 \mathrm{~F}$, administered as pretreatment, attenuates lung injury and pulmonary gas exchange impairment in rabbits challenged with PMA.

Contrary to our expectation, U-74389F did not prevent lung lipid peroxidation induced by PMA administration. Indeed, TBARS concentration in the lungs of U-74389F pretreated animals was increased by $50 \%$ over that measured in DMSO-injected controls, as it was in rabbits given PMA alone. The above findings suggest that mechanisms other than inhibition of lipid peroxidation are responsible for the protective effect exerted by $\mathrm{U}-74389 \mathrm{~F}$ in this animal model of lung injury.

As shown in table 2, the degree of alveolar haemorrhage and protein extravasation was significantly less severe in rabbits pretreated with $\mathrm{U}-74389 \mathrm{~F}$ than in those 
receiving PMA alone. Because PMA-induced lung injury is associated with a remarkable increase in pulmonary vascular pressure and pulmonary vascular resistance [21, 22 ], it could be hypothesized that U-74389F prevented or attenuated the pulmonary hypertensive response elicited by PMA. Although there are no data in the literature indicating that lazaroids are capable of reducing PMA-elicited pulmonary hypertension, we cannot, at present, rule out this possibility. However, it seems unlikely that this can be the sole mechanism by which U$74389 \mathrm{~F}$ exerts its protective effect because pulmonary vascular hypertension, in itself, does not appear to be sufficient for the full development of PMA-induced lung injury. As indicated by experiments in isolated perfused rabbit lungs, severe pulmonary arterial hypertension is observed when PMA is added to the perfusate in the absence of neutrophils, but this haemodynamic effect is not accompanied by significant increases in lung weight or lung lavage albumin concentration [23]. Furthermore, pulmonary capillary permeability, as measured by the capillary filtration coefficient, increases in isolated rat lungs when neutrophils in the perfusate are stimulated by PMA but not when PMA alone is added to a cell-free perfusate [22]. Finally, rabbits made granulocytopenic by injection of nitrogen mustard, do not develop any significant change in lung weight $[16,23]$, nor do they exhibit any significant increase in lung lavage cellularity or albumin concentration in response to PMA challenge $[16,23]$. These data support the concept that neutrophils are crucial to the development of lung injury following PMA administration.

As indicated by BAL studies, pretreatment with U$74389 \mathrm{~F}$ reduced by approximately $60 \%$ the neutrophil recruitment into alveolar spaces of rabbits given PMA (table 2). This finding cannot be attributed to inhibition of intravascular neutrophil aggregation and subsequent intrapulmonary sequestration because U-74389F had no effect in preventing PMA-induced leucopenia (fig. 1). In fact, in rabbits given PMA, regardless of whether they were or were not pretreated with U-74389F, the cumulative number of neutrophils in histological sections of the lung parenchyma was fivefold greater than that of control rabbits. Yet, in U-74389F pretreated animals, significantly more neutrophils were retained in extra-alveolar vessels and far fewer gained access to alveolar spaces than in rabbits given PMA alone (fig. 3). These data suggest that U-74389F may interfere with the process of neutrophil migration into pulmonary alveoli.

IL-8, a $8.4 \mathrm{kDa}$ polypeptide, is a potent chemoattractant and granule release stimulus for neutrophils [24]. IL-8 expression is induced in vitro in a variety of cells, including endothelial cells, alveolar epithelial cells, alveolar macrophages and pulmonary fibroblasts, in response to stimulation with proinflammatory cytokines (interleukin- 1 and tumour necrosis factor- $\alpha$ ) and to lipopolysaccharide [25-28]. Over the last few years, it has become increasingly evident that IL-8 plays an important role in the alveolar recruitment of neutrophils in the course of acute inflammatory lung disorders [12-15]. Because it has been reported that hyperoxia-stimulated, monocytederived IL-8 expression is suppressed in vitro by U$74389 \mathrm{~F}$ [11], we looked for evidence of in vivo IL-8 release in response to PMA challenge and for a possible modulation of its production by $\mathrm{U}-74389 \mathrm{~F}$ pretreatment.
As shown in figure 4, IL-8 became detectable in the plasma within 60 min of PMA administration, a time period comparable to that required to induce in vitro IL8 messenger ribonucleic acid (mRNA) expression in endothelial cells, pulmonary epithelial cells, and alveolar macrophages stimulated with lipopolysaccharide and proinflammatory cytokines [25-27]. IL-8 peak concentration in plasma occurred at 120 min after PMA injection and coincided with the development of arterial blood gas abnormalities. This suggests that IL- 8 may be implicated in the derangement of pulmonary gas exchange in this model of lung injury. By $120 \mathrm{~min}$ after PMA administration, circulating levels of IL-8 in U-74389F pretreated animals were significantly lower than those of rabbits receiving PMA alone (fig. 4). Likewise, the concentration of IL-8 in BAL was significantly lower in U-74389F pretreated rabbits than in those given PMA alone (table 2 ). Hence, the partial inhibition of neutrophil migration into pulmonary distal airspaces observed in lazaroid-pretreated rabbits may, in part, be due to downregulation of IL-8 production by $\mathrm{U}-74389 \mathrm{~F}$.

However, it should be emphasized that detection of IL-8 protein in BAL provides an indication of the net accumulation of this cytokine in excess of that required for receptor-binding but fails to provide information about the cell types responsible for its production. To substantiate the role of IL- 8 in this animal model of lung injury and to further characterize the modulatory effect of $\mathrm{U}-74389 \mathrm{~F}$ on IL-8 production, it would be appropriate to quantify IL- 8 gene expression by pulmonary cells (e.g. alveolar macrophages) in rabbits challenged with PMA and to compare cytokine mRNA levels with those of rabbits pretreated with U-74389F.

In conclusion, the present data indicate that lazaroid U-74389F attenuates phorbol myristate acetate induced lung injury in rabbits. This protective effect may, in part, be related to inhibition of neutrophil migration into pulmonary alveoli. In perspective, lazaroids may prove useful in preventing lung injury in critically ill patients at risk for adult respiratory distress syndrome.

\footnotetext{
Acknowledgements: The authors wish to thank C. Prontera and A. Perissinotto for their excellent technical assistance. The 21-aminosteroid compound was generously provided by D. Zimmermann of the Upjohn Company (Kalamazoo, MI, USA).
}

\section{References}

1. Braughler JM, Pregenzer JF, Chase RL, Duncan LA, Jacobsen EJ, McCall JM. Novel 21-aminosteroids as potent inhibitors of iron-dependent lipid peroxidation. $J$ Biol Chem 1987; 22: 10438-10440.

2. Audus KL, Guillot FL, Braughler JM. Evidence for 21aminosteroid association with the hydrophobic domains of brain microvessel endothelial cells. Free Rad Biol Med 1991; 11: 361-371.

3. Hall ED, Yonkers PA, McCall JM, Braughler JM. Effects of the 21-aminosteroid lipid peroxidation inhibitor U74006F on experimental head injury in mice. J Neurosurg 1988; 68: 456-461.

4. Hall ED, Pazara KE, Braughler JM. 21-aminosteroid lipid peroxidation inhibitor U74006F protects against cerebral ischemia in gerbils. Stroke 1988; 19: 997-1002. 
5. Haynes J Jr, Seibert A, Bass JB, Taylor AE. U74500A inhibition of oxidant-mediated lung injury. Am J Physiol 1990; 259: H144-H148.

6. Carrea FP, Lesnefsky EJ, Kaiser DG, Horwitz LD. The lazaroid U74006F, a 21-aminosteroid inhibitor of lipid peroxidation, attenuates myocardial injury from ischemia and reperfusion. J Cardiovasc Pharmacol 1992; 20: 230235.

7. Hall ED, Yonkers PA, McCall JM. Attenuation of hemorrhagic shock by the nonglucocorticoid 21-aminosteroid U74006F. Eur J Pharmacol 1988; 147: 299-303.

8. Tanigaki T, Suzuki Y, Heimer D, Sussman HH, Ross WG, Raffin TA. Attenuation of acute lung injury and oxygen radical production by the 21-aminosteroid, U78518F. J Appl Physiol 1993; 74: 2155-2160.

9. McLaughlin GE, Frank L. Effects of the 21-aminosteroid, U-74389 F, on bleomycin-induced pulmonary fibrosis in rats. Crit Care Med 1994; 22: 313-319.

10. Thomas PD, Mao GD, Rabinovitch A, Poznansky MJ. Inhibition of superoxide-generating NADPH oxidase of human neutrophils by lazaroids (21-aminosteroids and 2methylaminochromans). Biochem Pharmacol 1993; 45: 241-251.

11. Metinko AP, Kunkel SL, Burdick MD, Strieter RM. Hyperoxia-induced monocyte-derived interleukin-8 expression is suppressed by the 21 -aminosteroids U-83836E and U-74389F. FASEB $J$ 1993; 7(3): A494.

12. Carrè PC, Mortenson RL, King TE Jr, Noble PW, Sable CL, Riches DWH. Increased expression of the interleukin-8 gene by alveolar macrophages in idiopathic pulmonary fibrosis: a potential mechanism for the recruitment and activation of neutrophils in lung fibrosis. J Clin Invest 1991; 88: 1802-1810.

13. Lynch JP III, Standiford TJ, Rolfe MW, Kunkel SL, Strieter RM. Neutrophilic alveolitis in idiopathic pulmonary fibrosis: the role of interleukin-8. Am Rev Respir Dis 1992; 145: 1433-1439.

14. Miller EJ, Cohen AB, Nagao S, et al. Elevated levels of NAP-1/interleukin- 8 are present in the airspaces of patients with the adult respiratory distress syndrome and are associated with increased mortality. Am Rev Respir Dis 1992; 146: 427-432.

15. Donnelly SC, Strieter RM, Kunkel SL, et al. Interleukin8 and development of adult respiratory distress syndrome in at-risk patient groups. Lancet 1993; 341: 643-647.
16. Taylor RG, McCall CE, Thrall RS, Woodruff RD, O'Flaherty JT. Histopathologic features of phorbol myristate acetateinduced lung injury. Lab Invest 1985; 52: 61-70.

17. Ohkawa H, Ohishi N, Yagi K. Assay of lipid peroxides in animal tissue by thiobarbituric acid reaction. Anal Biochem 1979; 95: 351-358.

18. Esterbauer H, Cheeseman KH. Determination of aldehydic lipid peroxidation products: malondialdehyde and 4-hydroxynonenal. Methods Enzymol 1990; 186: 407-421.

19. Wills ED. Lipid peroxide formation in microsomes. Biochem J 1969; 113: 315-324.

20. Yoshimura T, Yuhki N. Neutrophil attractant/activation protein-1 and monocyte chemoattractant protein-1 in rabbit: cDNA cloning and their expression in spleen cells. J Immunol 1991; 146: 3483-3488.

21. Loyd JE, Newman JH, English D, Ogletree ML, Meyrick BO, Brigham KL. Lung vascular effects of phorbol myristate acetate in awake sheep. $J$ Appl Physiol: Respirat Environ Exercise Physiol 1983; 54: 267-276.

22. Perry ML, Kayes SG, Barnard JW, Taylor AE. Effects of phorbol myristate acetate-stimulated human leukocytes on rat lung. J Appl Physiol 1990; 68: 235-240.

23. Shasby DM, Vanbenthuysen KM, Tate RM, Shasby SS, McMurtry I, Repine JE. Granulocytes mediate acute edematous lung injury in rabbits and in isolated rabbit lungs perfused with phorbol myristate acetate: role of oxygen radicals. Am Rev Respir Dis 1982; 125: 443-447.

24. Leonard EJ, Yoshimura T. Neutrophil attractant/activation protein-1 (NAP-1 (interleukin-8)). Am J Respir Cell Mol Biol 1990; 2: 479-486.

25. Strieter RM, Kunkel SL, Showell HJ, et al. Endothelial cell gene expression of a neutrophil chemotactic factor by TNF- $\alpha$, LPS and IL-1 $\beta$. Science 1989; 243 : 1467-1469.

26. Standiford TJ, Kunkel SL, Basha MA, et al. Interleukin8 gene expression by a pulmonary epithelial cell line: a model for cytokine networks in the lung. J Clin Invest 1990; 86: 1945-1953.

27. Strieter RM, Chensue SW, Basha MA, et al. Human alveolar macrophage gene expression of interleukin- 8 by tumor necrosis factor- $\alpha$, lipopolysaccharide and interleukin-1ß. Am J Respir Cell Mol Biol 1990; 2: 321-326.

28. Rolfe MW, Kunkel SL, Standiford TJ, et al. Pulmonary fibroblast expression of interleukin-8: a model for alveolar macrophage-derived cytokine networking. Am J Respir Cell Mol Biol 1991; 5: 493-501. 